\title{
Effectiveness of Breast and Eye Shielding During Cervical Spine Radiography: An Experimental Study
}

This article was published in the following Dove Press journal: Risk Management and Healthcare Policy

\section{Wiam Elshami (D) \\ Mohamed M Abuzaid (ID $\mathrm{H} O$ Tekin}

Medical Diagnostic Imaging Department, College of Health Sciences, University of Sharjah, Sharjah, United Arab Emirates
Correspondence: Wiam Elshami Email welshami@sharjah.ac.ae
Purpose: This study assessed the effectiveness of breast and eye shielding and measured the radiation dose to radiosensitive tissues (eyes and breasts) due to scatter radiation during cervical spine X-ray radiography examinations.

Methods: Using an anthropomorphic phantom, the scattered radiation dose was measured before and after the placement of the lead shield over the eyes and breasts in the anteroposterior (AP) and left lateral projection. A regression formula was utilized to determine the exposure. Mean values and standard deviation of breasts and eyes doses were calculated. The paired two sample t-test was used to compare the recorded dose before and after shielding placement.

Results: Radiation shielding of eyes and breasts during AP cervical spine X-ray decreased radiation dose to the breasts by $99.9 \%$ and to the left and right eye by $91 \%$ and $89 \%$, respectively. For the left lateral cervical spine X-ray, the radiation dose decreased by $26 \%$ and $31 \%$ for the left and right eye, respectively, and by $23 \%$ and $99 \%$ for the left and right breast, respectively. A significant difference was noted comparing the dose before and after the implementing shielding on the eye and breast.

Conclusion: According to the results presented, the dose is significantly reduced, especially considering that they are not in the area of interest but are exposed to scatter radiation.

Keywords: radiation exposure, radiation dose, radiation protection, ALARA, radiography

\section{Introduction}

The ultimate goal of the health care system is to provide quality care in a safe environment. ${ }^{1}$ Diagnostic radiology procedures play a vital role in the patient's care, and nearly all patients experience a justified radiological examination at some point during health care. ${ }^{2}$ Therefore, ensuring patient radiation protection during radiological procedures is paramount. The application of the Healthcare Failure Mode Effect Analysis (HFMEA) technique in risk assessment in the radiology department indicated that the priority is to provide clinically acceptable image quality at the lowest possible radiation dose to minimize the risk of unnecessary radiation exposure. ${ }^{3}$ Exposure to ionizing radiation increases the risk of benign and malignant tumors. ${ }^{4,5}$ As the number of radiological examinations increases, the risk of cancer to patients undergoing radiological investigation might also increase. ${ }^{6,7}$ Radiation dose monitoring ensures patient safety during radiological procedures. It is important to protect patients from radiation hazards and optimizing exposure to ionizing radiation. Radiation protection of patients during diagnostic imaging 
procedures is an integral part of radiology. The As Low As Reasonably Achievable (ALARA) principle is fundamental in minimizing radiation exposure to protect patients and workers. The ALARA principle has three componentsreduce exposure time, increase the distance from the radiation source, and employ shielding. ${ }^{8}$ Shielding is commonly used to reduce the radiation dose to patients and staff from scatter radiation. Its ability to reduce radiation transmission depends on its specification and manufacture. The synthesis and development of shielding materials is a fertile research area, and multiple investigations have been conducted to provide effective radiation protection tools. $^{9-11}$

Despite the considerable number of guidelines published by specialized radiation protection organizations and professional societies, some controversies remain regarding the utility and efficiency of shielding practice. Marsh and Solisky (2019) challenged radiographers to rethink patient shielding practice. They believed that patient shielding practice should be abandoned in radiology because the use of shielding in digital radiography can lead to patients receiving a higher dose. ${ }^{12}$ Similarly, Kaplan et al (2018) reported that gonad shielding was not effective and efficient for female patients, especially when incorrect use of lead shielding results in repeat exposures. Both papers concluded that it is more reasonable to avoid shielding of patients as it has no benefits and might increase chances of image repetition. ${ }^{12,13}$

It is essential to base the decision of not shielding patients on research evidence. Thus, whether shielding can be abandoned should be proved for all radiological examinations. ${ }^{14}$ Moreover, the International Commission of Radiation Protection (ICRP) recommends that dose optimization should be utilized when appropriate, and informed decisions about shielding should be taken as one size does not fit all. ${ }^{15}$

Radiation shielding, especially for critical organs, continues to be a hot topic for researchers. However, different types of shields and dose reduction methods are being investigated. ${ }^{9-13}$ This has encouraged us to perform this experimental investigation on the effectiveness of breasts and eyes shielding during Cervical Spine (CS) radiography. CS radiography is a frequent radiological examination undertaken to rule out cervical injures. Traumatic injuries result from accidents are one of the leading causes of death and disability in the young adult population in many countries. Spinal fractures are included among the multiple complications secondary to traumatic mechanisms. In many developed countries, disorders related to the spine are major causes of disability and death. ${ }^{16}$ In the USA, approximately $15 \%$ of adults reported having spine problems in 2005; and in Europe, over 100 million people are estimated to suffer from chronic musculoskeletal pain. ${ }^{17}$

The current study aimed to assess the effectiveness of breast and eye shielding, and to measure the radiation dose to sensitive tissues (breast and eye lens) due to scatter radiation during CS radiography examinations.

\section{Materials and Methods Design}

This is an experimental study conducted at the Medical Imaging Laboratory, University of Sharjah, in February 2020. The approval of the Institutional Research Ethics Committee was not required for this study. The experiment was performed using the Philips X-ray unit with 2.5-mm Al filtration. The machine uses a High-voltage generator with primary voltage of $400 \mathrm{~V} / 480 \mathrm{~V}( \pm 10 \%) ; 60 \mathrm{~Hz}, 3$-phase. The $\mathrm{x}$-ray tube has dual-focus rotating anode (0.6 and 1.2). The maximum tube voltage of $150 \mathrm{Kv}$ and exposure time ranges from $1 \mathrm{~ms}$ to $4 \mathrm{~s}$. The machine has a ceiling suspension tube, fixed vertical stand and the table movements is automated with height adjustment function. Quality control tests were performed before the study, and all imaging parameters were well within the equipment specifications and the international accepted limits. ${ }^{18}$

\section{Anthropomorphic Phantom}

The X-ray experiment used a female anthropomorphic phantom to simulate a patient and relative radiosensitive tissue. The phantom is a life-size human figure that mimics an adult patient aged 35 years old. It has a fully flexible articulated skeleton containing no metal parts, as well as internal representations of the larynx, heart, lungs and kidneys. The phantom can be positioned for all standard projections with no more difficulty than a difficult patient might present. The breasts were simulated by breast implants of $340 \mathrm{~mL}$ of saline solution positioned between the second and sixth ribs, and the medial edge was aligned with the edge of the sternum. ${ }^{19}$

\section{Imaging Procedure}

The experiment included CS radiographic examinations using the adult phantom in anteroposterior (AP) and left lateral CS (Figure 1). Imaging procedures were performed according to Merrill's Atlas of Radiographic Positioning 

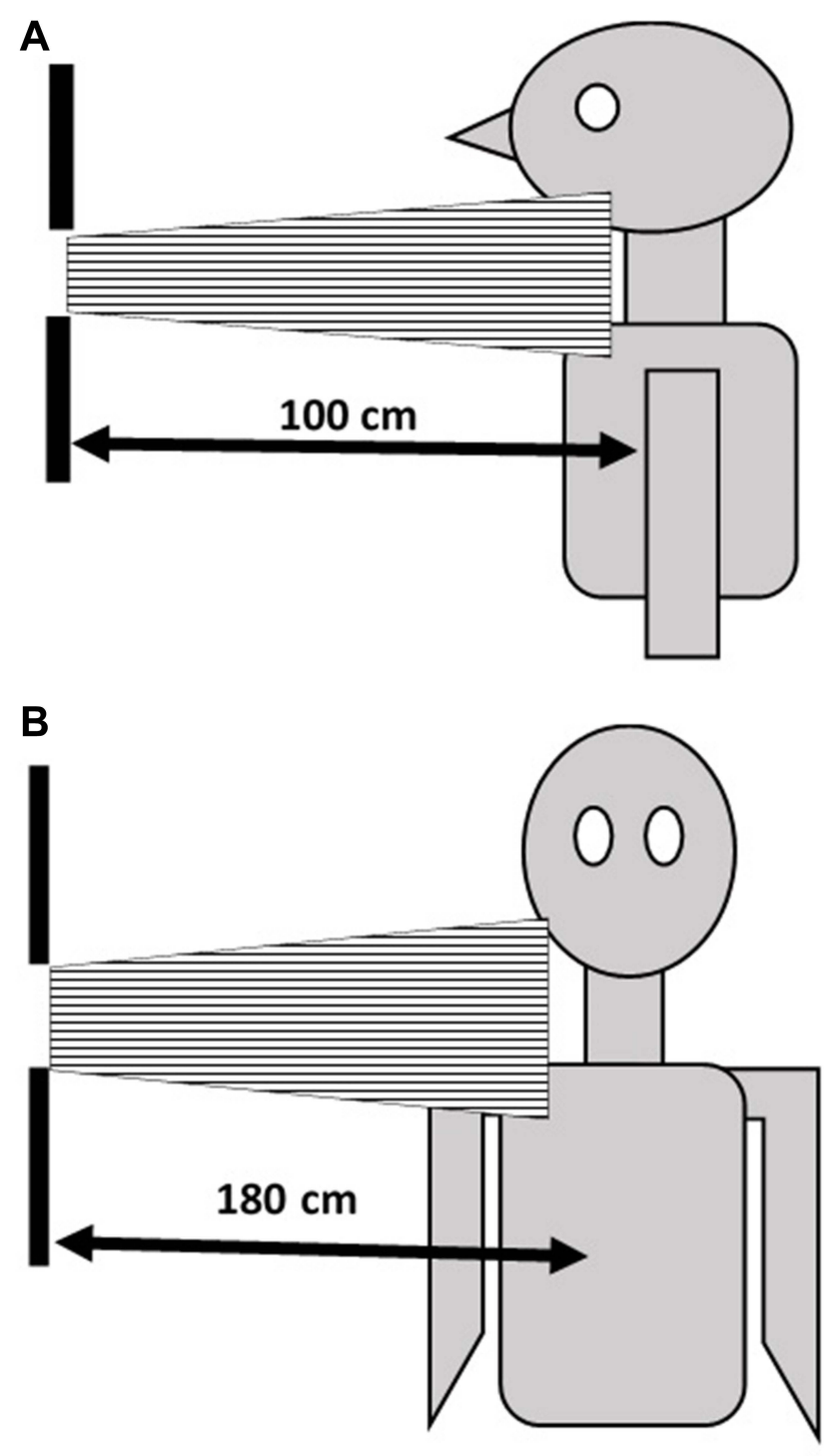

Figure I Schematic of X-ray beams in (A) anteroposterior cervical spine and (B) lateral cervical spine.

and Procedures. ${ }^{20}$ The technique used fine focus and $18 \mathrm{X}$ $24 \mathrm{~cm}$ field of view for AP and left lateral CS radiography examinations. The KVp was set at 70 and the focus detector distance was $100 \mathrm{~cm}$ for AP CS. In the left lateral, the $\mathrm{KVp}$ was set at 77 and the focus detector distance was $180 \mathrm{~cm}$.

\section{Dose Measurements}

The absorbed radiation dose was measured using a Piranha dosimeter that has internal and external detectors (RTI Electronic AB, Sweden). It had been calibrated in RTI Electronics Calibration Laboratory in January 2020. The Piranha external dose detector was used in the current study to measure the absorbed dose and rate (Figure 2).
A

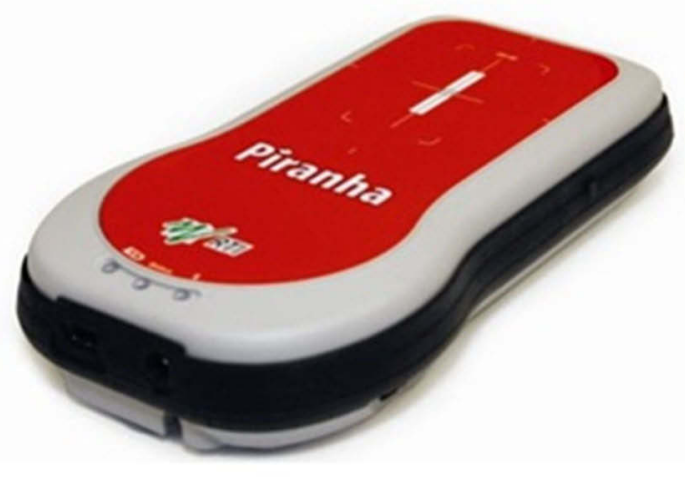

B

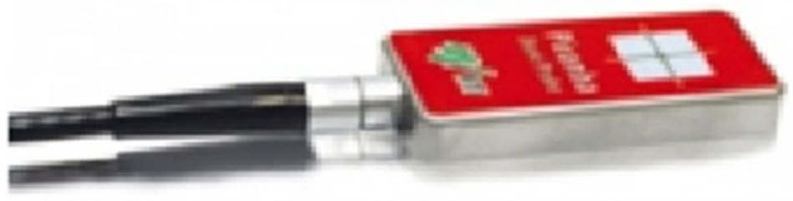

Figure 2 Piranha radiation dosimeter in (A) Piranha internal detector and (B) the Piranha external detector.

The dosing accuracy of the device is $\pm 5 \%$ over a range of $0.7-1000 \mathrm{~Gy}$, and the accuracy of the dose rate is $\pm 5 \%$ of reading over the range of $10-450 \mathrm{mGy} / \mathrm{s}$. Exposure time accuracy is $\pm 1 \%$ of reading $\pm 0.5 \mathrm{~ms}$ over the range of 0.1 ms to $2000 \mathrm{~s}$.

The intensity of the X-ray beam reduces as energy is either absorbed or scattered in the matter. ${ }^{21}$ Therefore, the levels of absorbed or scattered radiation were undetected using clinically relevant mAs (3.20 mAs). Hayre (2018) illustrated a useful method for data collection and analysis. The increase of $\mathrm{mA}$ values allows the intensity of the $\mathrm{X}$-ray beam (number of electrons across the X-ray tube) to be received as quantifiable reading for analysis. ${ }^{22}$ This is represented by Equation (1) where the x-ray intensity is directly proportional to $\mathrm{mA}$. Consequently, an increase in $\mathrm{mA}$ significantly increased both quantity and intensity. Therefore, a regression formula should be applied to identify the corrected exposure. The regression formula is represented by Equation (2) where a is mean of exposure, $b$ is set $\mathrm{mAs}$, and $\mathrm{c}$ is clinically relevant $\mathrm{mAs}$ (3.20 mAs).

$$
\mathrm{I} \alpha \mathrm{mA}
$$

$$
\text { Corrected } \mathrm{mAs}=(\mathrm{a} / \mathrm{b}) * \mathrm{c}
$$

Other independent variables such as $\mathrm{kVp}$, source to image distance, focal spot size, and field size remained constant throughout the experiment. 
A

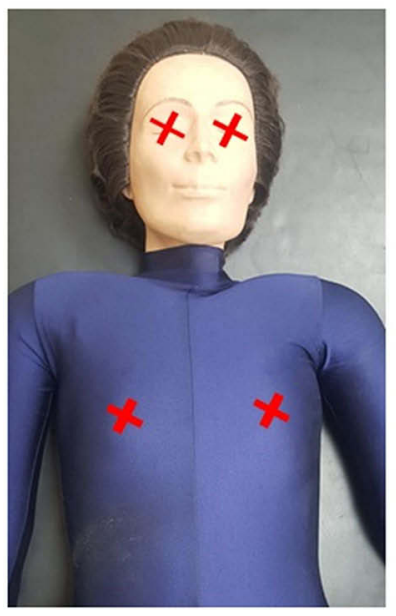

B

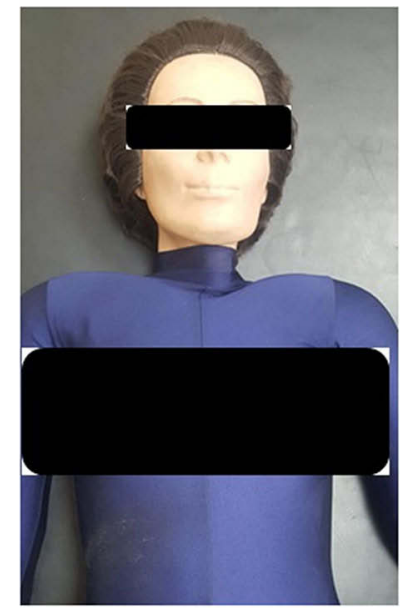

Figure 3 The anthropometric phantom shows the illustration of the external detector position to measure the absorbed dose in $(\mathbf{A})$ without shielding and (B) with shielding.

\section{Data Collection}

The detector was positioned at the level of the eye (right and left) and breast (right and left), and measurements were done for both AP and lateral CS radiography examination. Phantom positioned as described in the literature. ${ }^{20}$ Five consecutive exposures were undertaken to calculate the mean dose value, thus enhancing repeatability and precision of the methods used and decreasing any uncertainty.

The dose measurements were executed at two phases: 1) without shielding, and then 2) with shielding over the eyes and breasts (Figure 3). The detector was placed under the shielding and no readings were recorded in the right and left breasts during $\mathrm{AP}$, and on the right breast during lateral. Thus, the dose was below the dosimeter threshold and was represented by the value $<0.000$ throughout this paper.

\section{Statistical Analysis}

SPSS software (version 23.0; SPSS, USA) used for data analysis. The quantitative variables were described using mean \pm standard deviation. A $t$-test was used to compare different data obtained for each pair orientations. The differences were considered statistically significant at $\mathrm{p}<0.05$.

\section{Results}

The radiation dose during AP CS without shielding of eyes and breasts revealed that the average doses at left and right sides are almost similar, with an average of $6.87 \mu \mathrm{Gy}$ and $1.87 \mu \mathrm{Gy}$, respectively. The shielding of eyes and breasts during AP CS decreased radiation exposure by $99.9 \%$ for breasts and $91 \%$ and $89 \%$ for the left eye and right eye, respectively (Table 1).

Analysis of radiation dose during left lateral CS without shielding revealed that the left eye was exposed to 3.88 $\mu \mathrm{Gy}$, the right eye exposed to $2.89 \mu \mathrm{Gy}$, the left breast exposed to $0.98 \mu \mathrm{Gy}$, and the right breast exposed to 0.61 $\mu \mathrm{Gy}$. Shielding of the eyes and breasts during left lateral CS decreased the radiation exposure by $26 \%$ and $31 \%$ for the left and right eye, and by $23 \%$ and $99 \%$ for the left and right breast, respectively (Table 2 ). The $t$-test results, presented in Table 3, revealed that there is statistically significant dose reduction achieved upon implementing shielding on the eyes and breasts during AP and left lateral CS radiography examination with p-value $<0.05$.

The use of shielding on eyes and breasts in CS radiography reduced radiation dose absorbed by patients. Analysis of the dose in the left lateral CS radiography indicated that the dose reduction was higher on the right side compared to the left side.

\section{Discussion}

Ionizing radiation has a serious impact on living beings, from deterministic to stochastic effects. However, many medical applications such as diagnostic radiology, radiation therapy, and nuclear medicine require the use of ionizing radiations such as $\mathrm{x}$-rays and gamma rays. Accordingly, optimization and standardization of the radiation dose are important for patient dose reduction. Shielding is used in clinical practice to reduce the radiation dose to patients and it is essential for patient and staff safety. Different types of patient shielding tools for eye lens, breast, gonads, and thyroid are available and should be considered for patient safety.

Although several studies have investigated the reduction of the radiation dose as a result of shielding, ${ }^{13,15}$ the unique aspects of the current study were the implementation of shielding in a frequently performed imaging procedure and the protection of two radiosensitive organs (eye and breast) close to anatomical area of interest. Breast and eye lens are exposed to scatter radiation and they are not part from the image. Consequently, the application of shielding in the current study was out of the anatomy under investigation and therefore, it will not have negative effects on the image quality.

Employing shielding benefits the patient by reducing the absorbed dose. Almost $99 \%$ of the dose reduction was achieved in the right and left breast in the AP CS, while 
Table I Radiation Dose in $\mu$ Gy to Radiosensitive Organs During AP Cervical Spine Radiography

\begin{tabular}{|c|c|c|c|c|c|c|c|c|c|}
\hline \multirow[b]{2}{*}{ AP } & \multicolumn{4}{|c|}{ Without Shielding } & \multicolumn{4}{|c|}{ With Shielding } & \multirow[b]{2}{*}{$\begin{array}{l}\% \\
\text { Reduction }\end{array}$} \\
\hline & Exposure & $\begin{array}{l}\text { Corrected } \\
\text { Exposure }\end{array}$ & Average & SD & Exposure & $\begin{array}{l}\text { Corrected } \\
\text { Exposure }\end{array}$ & Average & SD & \\
\hline Lt eye & $\begin{array}{l}13.83 \\
13.76 \\
13.67 \\
13.69 \\
13.65\end{array}$ & $\begin{array}{l}6.92 \\
6.88 \\
6.83 \\
6.84 \\
6.82\end{array}$ & 6.86 & 0.038 & $\begin{array}{l}1.24 \\
1.23 \\
1.23 \\
1.24 \\
1.23\end{array}$ & $\begin{array}{l}0.62 \\
0.61 \\
0.61 \\
0.62 \\
0.61\end{array}$ & 0.62 & 0.003 & $91 \%$ \\
\hline Rt eye & $\begin{array}{l}13.90 \\
13.89 \\
13.42 \\
13.90 \\
13.65\end{array}$ & $\begin{array}{l}6.95 \\
6.94 \\
6.71 \\
6.95 \\
6.83\end{array}$ & 6.88 & 0.107 & $\begin{array}{l}1.72 \\
1.42 \\
1.65 \\
1.57 \\
1.54\end{array}$ & $\begin{array}{l}0.86 \\
0.71 \\
0.83 \\
0.79 \\
0.77\end{array}$ & 0.79 & 0.057 & $89 \%$ \\
\hline $\begin{array}{l}\text { Lt } \\
\text { breast }\end{array}$ & $\begin{array}{l}4.12 \\
4.05 \\
3.90 \\
3.98 \\
3.82\end{array}$ & $\begin{array}{l}2.06 \\
2.03 \\
1.95 \\
1.99 \\
1.91\end{array}$ & 1.99 & 0.059 & $<0.000$ & $<0.000$ & & & $99.9 \%$ \\
\hline $\begin{array}{l}\mathrm{Rt} \\
\text { breast }\end{array}$ & $\begin{array}{l}3.47 \\
3.47 \\
3.47 \\
3.48 \\
3.46\end{array}$ & $\begin{array}{l}1.73 \\
1.74 \\
1.73 \\
1.74 \\
1.73\end{array}$ & 1.74 & 0.004 & $<0.000$ & $<0.000$ & & & $99.9 \%$ \\
\hline
\end{tabular}

the left lateral CS had almost $99 \%$ and $23 \%$ dose reduction in the right and left breast, respectively. Connor et al (2018) stressed the importance of shielding to breast and gonads during AP abdominal X-ray, considering that breast and gonads are exposed to scatter radiation. The dose to the breast and gonads were reduced by $46 \%-93 \%$ and $13 \%-50 \%$, respectively. ${ }^{23}$ Similarly, Ciarmatori et al (2016) documented a significant dose reduction in the eye lens dose $(28.5 \pm 5 \%)$, and image quality was not affected by shielding during head Computed Tomography $(\mathrm{CT}){ }^{24}$ The radiation dose reduction up to $50 \%$ with no effect on image quality has been reported in eye during head $\mathrm{CT}^{25,26}$ Similar results were noted when shielding the breast in fluoroscopy, ${ }^{27} \mathrm{CT}$ head scan, ${ }^{28,29}$ and lumbar radiography examinations. ${ }^{19}$

The eye lens is highly radiosensitive, especially in children, but studies on the radiation dose to the eye lens are scarce and focused on CT. In the current study, the evaluation of the absorbed radiation dose by the eyes indicated that the dose was similar in the right and left eye in the AP CS, but was higher in the left eye than in the right eye in the left lateral CS. The dose in the lateral CS might be increased due to the increased thickness of the irradiated area. ${ }^{21}$
Several radiosensitive tissues such as the eye lens, thyroid gland, breast, and gonads may benefit from shielding. ${ }^{26}$ In CS radiography, the possibility of incorrect shield positioning is limited as the shield is never on the area under examination. Incorrect positioning of the gonad shielding during pelvic radiography in both women and men can lead to increased dose due to incomplete coverage of the gonads. ${ }^{30-32}$ Correspondingly, using shielding in pediatric patients undergoing pelvic examination may result in repeat imaging procedure if the shield blocks vital anatomy, which will increase the patient dose. ${ }^{30}$ The ICRP recommends that dose optimization should be utilized when appropriate and that informed decisions about shielding should be taken as one size does not fit all. ${ }^{15}$ Therefore, use of shielding should be undertaken individually for different radiology examinations. ${ }^{14}$

\section{Limitation of the Study}

The limitation of the study includes that the study is conducted on a phantom and not on a real patient and it does not account the image quality as breasts and eyes are out of area of interest. Also, variety of patients in terms of age, weight, height and gender were not investigated. Obviously, the results of this study are applicable to the 
Table 2 Radiation Dose in $\mu$ Gy to Radiosensitive Organs During Lateral Cervical Spine Radiography

\begin{tabular}{|c|c|c|c|c|c|c|c|c|c|}
\hline \multirow[b]{2}{*}{ Lateral } & \multicolumn{4}{|c|}{ Without Shielding } & \multicolumn{4}{|c|}{ With Shielding } & \multirow[b]{2}{*}{$\begin{array}{l}\% \\
\text { Reduction }\end{array}$} \\
\hline & Exposure & $\begin{array}{l}\text { Corrected } \\
\text { Exposure }\end{array}$ & Average & SD & Exposure & $\begin{array}{l}\text { Corrected } \\
\text { Exposure }\end{array}$ & Average & SD & \\
\hline Lt eye & $\begin{array}{l}7.79 \\
7.74 \\
7.75 \\
7.76 \\
7.77\end{array}$ & $\begin{array}{l}3.89 \\
3.87 \\
3.87 \\
3.88 \\
3.88\end{array}$ & 3.88 & 0.010 & $\begin{array}{l}5.66 \\
5.78 \\
5.76 \\
5.78 \\
5.80\end{array}$ & $\begin{array}{l}2.83 \\
2.89 \\
2.88 \\
2.89 \\
2.90\end{array}$ & 2.88 & 0.028 & $26 \%$ \\
\hline Rt eye & $\begin{array}{l}5.82 \\
5.77 \\
5.74 \\
5.80 \\
5.75\end{array}$ & $\begin{array}{l}2.91 \\
2.88 \\
2.87 \\
2.90 \\
2.88\end{array}$ & 2.89 & 0.017 & $\begin{array}{l}3.75 \\
4.32 \\
4.25 \\
4.28 \\
3.36\end{array}$ & $\begin{array}{l}1.87 \\
2.16 \\
2.13 \\
2.14 \\
1.68\end{array}$ & 2.00 & 0.211 & $31 \%$ \\
\hline Lt breast & $\begin{array}{l}1.96 \\
1.96 \\
1.96 \\
1.98 \\
1.97\end{array}$ & $\begin{array}{l}0.98 \\
0.98 \\
0.98 \\
0.99 \\
0.99\end{array}$ & 0.98 & 0.005 & $\begin{array}{l}1.58 \\
1.52 \\
1.51 \\
1.50 \\
1.51\end{array}$ & $\begin{array}{l}0.79 \\
0.76 \\
0.76 \\
0.75 \\
0.76\end{array}$ & 0.76 & 0.015 & $23 \%$ \\
\hline $\begin{array}{l}\mathrm{Rt} \\
\text { breast }\end{array}$ & $\begin{array}{l}1.13 \\
1.03 \\
1.25 \\
1.33 \\
1.33\end{array}$ & $\begin{array}{l}0.57 \\
0.51 \\
0.62 \\
0.67 \\
0.67\end{array}$ & 0.61 & 0.067 & $<0.00$ & $<0.000$ & & & $99.9 \%$ \\
\hline
\end{tabular}

Table 3 Results of $t$-Tests

\begin{tabular}{|c|c|c|c|c|c|}
\hline $\begin{array}{l}\text { Cervical Spine } \\
\text { Radiography }\end{array}$ & Shielding & $\begin{array}{l}\text { Mean Dose } \\
(\mu \mathrm{Gy})\end{array}$ & $\begin{array}{l}\text { Std. } \\
\text { Deviation }\end{array}$ & $\begin{array}{l}\text { Std. Error } \\
\text { Mean }\end{array}$ & $\begin{array}{l}\text { P value (Two- } \\
\text { Tailed) }\end{array}$ \\
\hline AP & $\begin{array}{l}\text { Eyes without shielding } \\
\text { Eyes with shielding }\end{array}$ & $\begin{array}{l}6.867 \\
0.703\end{array}$ & $\begin{array}{l}0.07631 \\
0.10144\end{array}$ & $\begin{array}{l}0.02413 \\
0.03208\end{array}$ & 0.000 \\
\hline AP & $\begin{array}{l}\text { Breasts without shielding } \\
\text { Breasts with shielding }\end{array}$ & $\begin{array}{l}1.861 \\
<0.000\end{array}$ & $\begin{array}{l}0.1398 \\
0\end{array}$ & $\begin{array}{l}0.04421 \\
0\end{array}$ & 0.000 \\
\hline Lateral & $\begin{array}{l}\text { Left eye without shielding } \\
\text { Left eye with shielding }\end{array}$ & $\begin{array}{l}3.878 \\
2.878\end{array}$ & $\begin{array}{l}0.00837 \\
0.02775\end{array}$ & $\begin{array}{l}0.00374 \\
0.0124 I\end{array}$ & 0.000 \\
\hline Lateral & $\begin{array}{l}\text { Right eye without shielding } \\
\text { Right eye with shielding }\end{array}$ & $\begin{array}{l}2.888 \\
1.996\end{array}$ & $\begin{array}{l}0.01643 \\
0.21291\end{array}$ & $\begin{array}{l}0.00735 \\
0.09522\end{array}$ & 0.000 \\
\hline Lateral & $\begin{array}{l}\text { Left breast without } \\
\text { shielding } \\
\text { Left breast with shielding }\end{array}$ & $\begin{array}{l}0.984 \\
0.764\end{array}$ & $\begin{array}{l}0.00548 \\
0.01517\end{array}$ & $\begin{array}{l}0.00245 \\
0.00678\end{array}$ & 0.000 \\
\hline Lateral & $\begin{array}{l}\text { Right breast without } \\
\text { shielding } \\
\text { Right breast with shielding }\end{array}$ & $\begin{array}{l}0.608 \\
>0.000\end{array}$ & $\begin{array}{l}0.0687 \\
0\end{array}$ & $\begin{array}{l}0.03072 \\
0\end{array}$ & 0.001 \\
\hline
\end{tabular}

standard body size and might differ for other patients. Therefore, future researches are encouraged to assess a variety of patients as one size does not fit all.

\section{Conclusion}

In conclusion, the investigation of the effectiveness of breasts and eyes shielding during CS radiography reveals 
considerable reduction of the absorbed radiation dose to breasts and eye lens, which, in turn, will decrease the risk of cancer and biological changes. The breast and eye lens are exposed to scatter radiation as they are not in the area of interest; therefore, shielding them will not affect the image quality. The results of the current study highlighted the importance of radiation shielding in CS radiography. Proper shielding practices should be included in technologist education and continuing education programs. Further research is recommended for better clinical decision making, and shielding cannot be abandoned for all types of imaging.

\section{Disclosure}

The authors report no conflicts of interest in this work.

\section{References}

1. McKee M, Healy J. The role of the hospital in a changing environment. Bull World Health Organ. 2000;78(6):803-810.

2. Lim B. Radiation exposure dose on persons engaged in radiation-related industries in Korea. $J$ Radiol Sci Technol. 2006;29 (3):185-195.

3. Mugi K, C PK, Pintelon L. Application of HFMEA on risk assessment of radiology processes in public hospitals: a case study of Nyeri County Referral Hospital. 2018.

4. Kutanzi KR, Lumen A, Koturbash I, Miousse IR. Pediatric exposures to ionizing radiation: carcinogenic considerations. Int J Environ Res Public Health. 2016;13(11):1057. doi:10.3390/ijerph13111057

5. Fazel R, Krumholz HM, Wang Y, et al. Exposure to low-dose ionizing radiation from medical imaging procedures. $N$ Engl $J$ Med. 2009;361(9):849-857. doi:10.1056/NEJMoa0901249

6. Maghrabi HA, Deb P, Vijayan A, Wang L. An overview of lead aprons for radiation protection: are they doing their best. 2015 .

7. Mohammed S, Rosenkrantz AB. Providing compassionate care for the elderly patient in radiology. Curr Probl Diagn Radiol. 2020;49 (2):67-69. doi:10.1067/j.cpradiol.2019.02.001

8. Vano E. ICRP recommendations on managing patient dose in digital radiology. Radiat Prot Dosimet. 2005;114(1-3):126-130. doi:10. 1093/rpd/nch533

9. Uosif M, Mostafa A, Issa SA, Tekin HO, Alrowaili ZA, Kilicoglu O. Structural, mechanical and radiation shielding properties of newly developed tungsten lithium borate glasses: an experimental study. $J$ Non Cryst Solids. 2020;532:119882. doi:10.1016/j.jnoncrysol. 2019.119882

10. Abuzaid MM, Susoy G, Issa SA, Elshami W, Kilicoglu O, Tekin HO. Relationship between melting-conditions and gamma shielding performance of fluoro-sulfo-phosphate (FPS) glass systems: a comparative investigation. Ceram Int. 2020;46(10):15255-15269. doi:10.1016/j.ceramint.2020.03.065

11. Susoy G, Guclu EA, Kilicoglu O, et al. The impact of $\mathrm{Cr} 2 \mathrm{O} 3$ additive on nuclear radiation shielding properties of LiFâ€"SrOâ €"B2O3 glass system. Mater Chem Phys. 2020;242:122481. doi:10.1016/j.matchemphys.2019.122481

12. Marsh RM, Silosky M. Patient shielding in diagnostic imaging: discontinuing a legacy practice. Am J Roentgenol. 2019;212 (4):755-757. doi:10.2214/AJR.18.20508
13. Kaplan SL, Magill D, Felice MA, Xiao R, Ali S, Zhu X. Female gonadal shielding with automatic exposure control increases radiation risks. Pediatr Radiol. 2018;48(2):227-234. doi:10.1007/s00247-017-3996-5

14. van der Merwe B. Shielding of patients, foolish or reasonable? $S$ Afr Radiographer. 2019;57(1):5-6.

15. Khong PL, Ringertz H, Donoghue V, et al. ICRP publication 121: radiological protection in paediatric diagnostic and interventional radiology. Ann ICRP. 2013;42(2):1-63. doi:10.1016/j.icrp.2012.10.001

16. MÁC C, Cadena JLR, Romero R, et al. Frequency of vertebral fractures in high-energy trauma. Coluna/Columna. 2018;17 (2):147-150. doi:10.1590/s1808-185120181702189443

17. Tahvonen P, Oikarinen H, Niinimäki J, Liukkonen E, Mattila S, Tervonen O. Justification and active guideline implementation for spine radiography referrals in primary care. Acta Radiol. 2017;58 (5):586-592. doi:10.1177/0284185116661879

18. Papp J. Quality Management in the Imaging Sciences E-Book. Elsevier Health Sciences; 2018.

19. MekiÅ $i$ N, Zontar D, Skrk D. The effect of breast shielding during lumbar spine radiography. Radiol Oncol. 2013;47(1):26-31. doi:10.2478/raon-2013-0004

20. Frank ED, Long BW, Smith BJ. Merrill's Atlas of Radiographic Positioning and Procedures. Vol. 3. Elsevier; 2018.

21. Bushong SC. Radiologic Science for Technologists-E-Book: Physics, Biology, and Protection. Elsevier Health Sciences; 2013.

22. Hayre C, Bungay H, Jeffery C, Cobb C, Atutornu J. Can placing lead-rubber inferolateral to the light beam diaphragm limit ionising radiation to multiple radiosensitive organs? Radiography. 2018;24 (1):15-21. doi:10.1016/j.radi.2017.09.002

23. Connor M, Arrigo A, Kierans Z, et al. An analysis of breast and gonad lead shielding effectiveness in abdominal AP radiography: a phantom study. OPTIMAX Ebook. 2018;128-142.

24. Ciarmatori A, Nocetti L, Mistretta G, Zambelli G, Costi T. Reducing absorbed dose to eye lenses in head CT examinations: the effect of bismuth shielding. Aust Phys Eng Sci Med. 2016;39(2):583-589. doi:10.1007/s13246-016-0445-y

25. Hopper KD, Neuman JD, King SH, Kunselman AR. Radioprotection to the eye during CT scanning. Am J Neuroradiol. 2001;22 (6):1194-1198.

26. Chavideh M, Khorshidi SR, Baghmalek AB, et al. Prevalence of shielding in diagnostic X-ray centers in the Islamic Republic of Iran: a systematic review. Mod Health Sci. 2019;2(2):p38. doi:10.30560/mhs.v2n2p38

27. Fordham LA, Brown ED, Washburn D, Clark RL. Efficacy and feasibility of breast shielding during abdominal fluoroscopic examinations. Acad Radiol. 1997;4(9):639-643. doi:10.1016/S10766332(05)80269-7

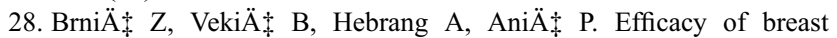
shielding during $\mathrm{CT}$ of the head. Eur Radiol. 2003;13 (11):2436-2440. doi:10.1007/s00330-003-1945-1

29. Beaconsfield T, Nicholson R, Thornton A, Al-Kutoubi A. Would thyroid and breast shielding be beneficial in CT of the head? Eur Radiol. 1998;8(4):664-667. doi:10.1007/s003300050456

30. Karami V, Zabihzadeh M, Shams N, Malehi AS. Gonad shielding during pelvic radiography: a systematic review and meta-analysis. Arch Iran Med. 2017;20:2.

31. Davies BH, Manningâ E, Stanley AS, Hughes VJ, Ward AJ. The impact of gonad shielding in anteroposterior (AP) pelvis projections in an adult: a phantom study utilising digital radiography (DR). Radiography. 2020.

32. McKenney S, Gingold E, Zaidi H. Gonadal shielding should be discontinued for most diagnostic imaging exams. Med Phys. 2019;46(3):1111-1114. doi:10.1002/mp.13409 


\section{Publish your work in this journal}

Risk Management and Healthcare Policy is an international, peerreviewed, open access journal focusing on all aspects of public health, policy, and preventative measures to promote good health and improve morbidity and mortality in the population. The journal welcomes submitted papers covering original research, basic science, clinical \& epidemiological studies, reviews and evaluations, guidelines, expert opinion and commentary, case reports and extended reports. The manuscript management system is completely online and includes a very quick and fair peer-review system, which is all easy to use. Visit http://www.dovepress.com/testimonials.php to read real quotes from published authors.

Submit your manuscript here: https://www.dovepress.com/risk-management-and-healthcare-policy-journal 